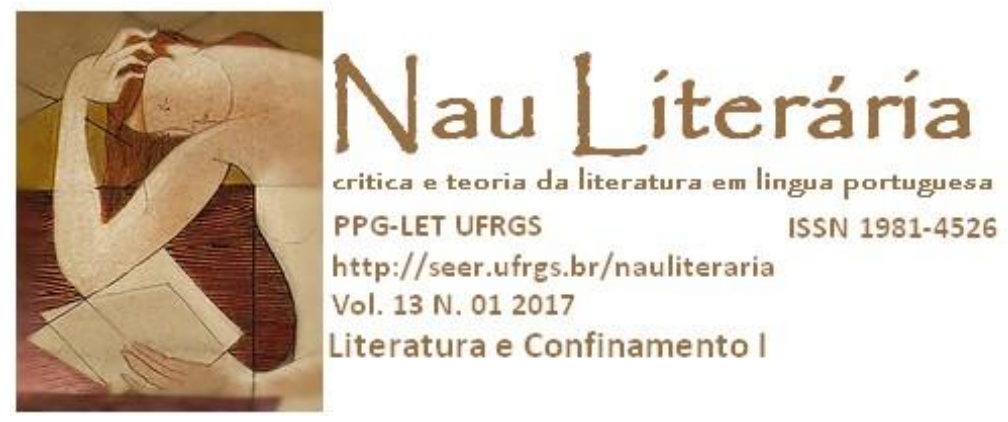

\title{
O trauma, a memória e a pedra
}

Lucas Antônio de Carvalho Cyrino

\begin{abstract}
Resumo: A obra $O$ que os cegos estão sonhando?, de Noemi Jaffe, é ponto de partida e de chegada do estudo que propomos neste artigo. Observamos os três textos e as três vozes que a compõe - de Lili Jaffe, Noemi Jaffe e Leda Cartum, mãe, filha e neta - buscando resgatar a memória da experiência traumática de Lili nos campos de concentração nazistas, narradas em diário, como ponto convergente e de certa forma fundamental na existência de cada uma das narradoras. Considerando o relato de Lili como o testemunho escrito de uma sobrevivente do Holocausto, memória e trauma ocupam o eixo central do debate.
\end{abstract}

Palavras-chave: Memória; Trauma; Testemunho.

Abstract: The book $O$ que os cegos estão sonhando?, by Noemi Jaffe, is the point of departure and arrival of the study that we propose in this paper. We observe the three texts and the three voices that composes it - Lili Jaffe, Noemi Jaffe and Leda Cartum, mother, daughter and granddaughter - seeking to rescue the memory of the traumatic experience of Lili in the Nazi concentration camps, narrated in diary, as a converging point and in a certain way fundamental on the existence of each one of the narrators. Considering Lili's story as a written testimony of a survivor of the Holocaust, memory and trauma occupy the central axis of the debate.

Keywords: Memory. Trauma. Testimony.

No meio do caminho tinha uma pedra tinha uma pedra no meio do caminho

No meio do caminho, Carlos Drummond de Andrade ${ }^{1}$

Uma interpretação bastante simples dos primeiros versos do poema de Drummond permite que reconheçamos a pedra como um obstáculo, como uma adversidade que se impõe diante do caminho de alguém - neste caso, do eu-lírico. O uso do verbo ter no pretérito imperfeito do indicativo denota que essa pedra - esse obstáculo - se apresentava, no passado, de maneira senão contínua, pelo menos frequente, e que de alguma forma deixa uma sequela nesse eu-lírico, notada, num primeiro momento, pela repetição cíclica e quase consecutiva da

\footnotetext{
${ }^{1} 2013$, p. 36.
} 
imponente informação: "tinha uma pedra no meio do caminho"; e pela afirmação dada nos versos seguintes: "Nunca me esquecerei desses acontecimentos/ na vida de minhas retinas tão fatigadas". Esses acontecimentos, por sua vez, podem ser de toda ordem: uma doença, uma decepção, uma desilusão amorosa, uma derrota no jogo ou na política, a morte, para citar alguns exemplos. Às vezes, porém, essa pedra pode ser a metáfora de uma grande adversidade para todo o conjunto da sociedade ou mesmo da humanidade, respingando, obviamente, na "vida das retinas tão fatigadas" de cada indivíduo. Às vezes há uma guerra no meio do caminho. A guerra é a pedra no meio do caminho de Lili Jaffe, mãe de Noemi Jaffe, avó de Leda Cartum - filha de Noemi -, todas vozes narradoras da obra $O$ que os cegos estão sonhando $?^{2}$, permeada senão pela temática da guerra, pelo menos por sua sequela, pelos acontecimentos adversos do passado de Lili que ainda são importantes para a trajetória da filha e da neta, ainda que de modos distintos.

A partir da experiência de Lili Jaffe nos campos de concentração nazistas, narradas em seu diário - alocado na primeira parte da obra -, o estudo a seguir pretende resgatar dessa experiência - ou desse trauma, para começar a usar um termo que será aqui recorrente - a memória, ponto central para o qual convergem os discursos e as vidas das demais narradoras. Considerando o relato de Lili como o testemunho escrito de uma sobrevivente do Holocausto, memória e trauma ocupam o eixo central do debate sobre $O$ que os cegos estão sonhando?, obra que ainda compreende o relato de Noemi Jaffe e de Leda Cartum em relação a essa memória compartilhada.

\section{0 diário de Lili Jaffe}

Do ponto de vista de sua estrutura, a narrativa de Lili, na primeira parte do livro, é caracterizada por uma mescla de diário e memória, talvez melhor definido - embora não tão facilmente - como um diário a posteriori, já que sua redação se deu após a libertação dos campos de concentração. Esse material foi escrito com o intuito de "dar a sensação de que [os fatos] eram narrados enquanto estavam sendo vividos" (JAFFE, 2012, p. 8), ato impensável durante o período da guerra por fatores bastante óbvios, a começar por não haver papel e

\footnotetext{
${ }^{2}$ Embora a obra compreenda o conjunto de textos escritos por essas três gerações de mulheres, é importante desde já salientar que a responsabilidade editorial é dada a Noemi Jaffe - talvez por interesse de mercado, dado o reconhecimento já existente em relação ao seu trabalho como escritora e crítica literária. No entanto, mesmo que avaliar o peso ou a importância de cada texto para o conjunto da obra, um em relação ou em detrimento do outro, seja uma tarefa injusta, pode ser, ainda, que essa atribuição editorial seja um caminho para indicar certo protagonismo de Noemi dentro do contexto proposto - o que poderá ser visível em alguns momentos na análise que segue, embora a intenção não seja deliberadamente essa.
} 
caneta à disposição dos prisioneiros do Terceiro Reich. Embora seja autora apenas da segunda parte da obra (que ainda se divide em uma terceira, como já dissemos anteriormente, escrita por Leda Cartum), Noemi é a referência editorial em relação ao suposto "tratamento literário" dado ao diário de sua mãe - daí que confesse, ainda no texto de apresentação, decidir manter aspectos particulares da escrita.

A escolha pelo gênero diário por vezes esbarra o limite da verossimilhança e abre margem para algumas - poucas - lacunas na compreensão. Isso pode ser notado de maneira simples quando se observam confusões na passagem cronológica entre algumas datas; por exemplo: em meio ao relato de traslado entre os campos de concentração de Auschwitz e Bergen-Belsen, que se inicia no dia 28 de outubro de 1944, segue-se uma indicação do mês de novembro sem data precisa e logo parte-se para o dia 13 do mesmo mês, retornando para 13 de outubro (indicado curiosamente com uma interrogação entre parênteses logo após o mês) e em seguida continuando no dia $1^{\circ}$ de dezembro (cf. JAFFE, 2012, p. 29-31). Teria Noemi reordenado a narrativa, forçando (acidentalmente?) a desordem cronológica, ou teria a própria Lili, em sua redação, indicado datas não propositalmente aleatórias para organizar suas memórias - pelo trauma, por um pequeno descuido, pela vontade de tentar lembrar ou de simplesmente dar alguma precisão histórica para a sua experiência?

Essas lacunas podem ser notadas de maneira um pouco mais complexa quando se procura reconhecer certa transição de um diário-memória a um diário que acompanha o tempo presente da narrativa, redigido diariamente - o que ocorre provavelmente entre maio e junho de 1945, quando Lili chega à Suécia e, de acordo com o relato de Noemi, começa a escrever o diário. A verossimilhança é quase forçada porque, diante da segunda observação, pode-se reconhecer certo "amadurecimento" narrativo inclusive em alguns aspectos da linguagem, pois a partir daí são pouco frequentes os casos em que a suposta "espontaneidade e intensidade" com que o diário foi escrito expressa "o uso peculiar, muitas vezes, das concordâncias de gênero e número" (JAFFE, 2012, p. 7-8), como afirma Noemi. Nesse caso, não fica claro se há edição explícita de Noemi e em que grau tal edição acontece, precisamente porque não se tem contato com o material originário.

Apesar disso, o leitor atento não é ingênuo a ponto de acreditar que o texto seja fiel à produção de Lili, tal e qual fora concebido, porque essa ingenuidade negaria a compreensão de informações explícitas na obra: o diário foi traduzido do sérvio, língua materna de Lili, e muito provavelmente recebeu tratamento editorial das mãos de Noemi. Fica por vezes difícil acreditar que Lili tenha sobrevivido a tantas "pedras no caminho", a tantas adversidades que, diante das diversas histórias que se ouvem, se leem e se assistem em relação aos campos de 
concentração, certamente a teriam conduzido à morte. A não ingenuidade do leitor se transforma, então, em uma espécie de acanhamento que se curva diante da narrativa em forma de reconhecido respeito, principalmente porque o diário de Lili - seja ele escrito a posteriori, seja ele editado, seja ele frágil em certos pontos da verossimilhança - é um testemunho do durante e do pós-guerra, é um testemunho de quem sobreviveu à barbárie. Na medida em que essa experiência se converte em registro escrito, há quem possa indiciá-lo como autobiografia do sobrevivente, dado que exprime, à primeira vista, trauma e memória em primeira pessoa, ou seja, experiências bastante íntimas de quem o relata. Não que se pretenda, aqui, discutir o gênero da narrativa e bater o martelo em uma ou outra definição, mas é preciso reconhecer que "o testemunho não deve ser confundido nem com o gênero autobiográfico nem com a historiografia - ele apresenta uma outra voz, um canto (ou lamento) paralelo, que se junta à disciplina histórica no seu trabalho de colher os traços do passado" (SELIGMANN-SILVA, 2005, p. 79).

O diário de Lili é um caminho para tal colheita no que diz respeito aos sobreviventes da barbárie que caracterizou o Holocausto - e essa barbárie é característica de um trauma, de uma pedra no meio do seu caminho. Com efeito,

a testemunha, além do inexprimível horror vivido, carrega a responsabilidade coletiva de representar todas as vítimas ausentes do trauma coletivo, com um pesado ônus na medida em que, como bem salienta Susan Suleiman (2008), o testemunho é sempre individual enquanto o trauma histórico é coletivo. (LEWGOY, 2010, p. 53)

Muito embora não se explore com profundidade, neste artigo, o potencial coletivo da narrativa testemunhal de Lili, o trauma histórico pode ser visível - e, no presente estudo, explorado - pelo menos em relação às suas descendentes. Se o trauma histórico é coletivo, é provável que a experiência traumática que se exprime do testemunho de Lili atinja com maior profundidade sua filha e sua neta. A pedra no caminho de Lili Jaffe ultrapassa a sua existência e se impõe à trajetória de Noemi e de Leda, porque a vida de cada uma delas só se tornou possível porque Lili sobreviveu. Voltaremos ao tema quando discutirmos a experiência da memória na consciência de Noemi e de Leda.

Reconhecido o diário como um testemunho, pode-se elevar a maturidade de Lili - que tinha rasos dezenove anos quando foi liberta - e reconhecer, também e principalmente, o quanto a redação do diário é permeada por um processo de humanização, de resgate (ou até mesmo de conhecimento) de si como ser humano. Exemplos são vários: em um vagão de trem, perto de Hamburgo/Alemanha, em passagem absolutamente chocante do dia 5 de abril 
de 1945, pouco tempo antes de ser liberta, Lili experimenta o que parece ser o limite da desumanização, não suportando principalmente a fome:

\begin{abstract}
Não estamos nem vivos nem mortos [...] Já tenho dificuldade para falar. Pedimos ao alemão que não nos torture mais; não queremos viver mais; que nos mate [...] Não sabemos se aguentaremos um dia mais sem comida. Faz seis dias que não comemos. Pedimos, chorando, que o alemão nos mate. (JAFFE, 2012, p. 38)
\end{abstract}

A narrativa que segue indica que o soldado acatará o pedido, agendando o fuzilamento para as três horas da tarde. Às cinco horas, porém, o mesmo soldado retorna e informa: “Crianças, vocês estão salvas. À noite, por volta das doze, chegarão dois caminhões de pão". O desfecho é tragicamente literário: "Passou da meia-noite e nada de pão. Gememos em voz alta, mas as nossas vozes não podem ser ouvidas de longe” (JAFFE, 2012, p. 38). Pouco tempo depois, ainda a caminho da libertação, e quando deixa de ser transportada em vagões de carga para viajar em um trem elétrico - com assentos forrados, de modo que pudessem, ela e os demais, viajar sentados - Lili choca o leitor: "pela primeira vez me senti semelhante a um ser humano" (JAFFE, 2012, p. 39). A redescoberta da própria humanidade provavelmente tem início aí, complementada na passagem com data de 5 de março (sem ano indicativo, mas que provavelmente é 1945) no navio que lhe levaria da Dinamarca em direção à Suécia, precisamente na cena em que observa o mar e reflete sobre a condição que lhe era acometida poucos dias antes dessa viagem:

O mar é lindo. Verde escuro, transparente. As gaivotas esvoaçam e eu observo tudo como num sonho. Liberdade maravilhosa. Não há mais cerca elétrica, ninguém nos vigia, comida quanta desejássemos [...] Sinto uma alegria até o fundo de minha alma, liberdade, e as lágrimas escorrem feito chuva. (JAFFE, 2012, p. 43)

É possível que o amadurecimento de Lili não seja consciente, pelo menos não concomitantemente à redação do diário, mas é saldo positivo de um tratamento terapêutico autossubmetido. Isso se vê de tal maneira a partir de um ponto de vista contemporâneo ao nosso tempo, pelo qual se sabe que a redação como reflexão escrita de obstáculos diversos retomando mais uma vez o poema de Drummond, de "pedras no caminho" - é recomendada na psicoterapia como forma de compreender fatos e emoções e tentar, na medida do possível, superar adversidades. Na mesma direção vem a afirmação de Bernardo Lewgoy, feita a partir dos estudos de Dominick LaCapra, de que "a narrativa remete para o trabalho de luto que, ao separar passado e presente, permite à vítima da violência elaborar, simbolizar e narrar o seu sofrimento, violência e perdas, libertando-se do peso da lembrança e habilitando o sujeito para a continuação de uma vida normal"' (2010, p. 53). 
Isso quer dizer, em outras palavras, que Lili Jaffe provavelmente teve o diário como seu caminho terapêutico para lidar com os traumas do campo de concentração - mesmo que inconscientemente, mesmo que a intenção consciente do registro tenha sido outra. $\mathrm{O}$ resultado, para além do seu amadurecimento e humanização, reflete-se hoje em uma obra singular, cujos nós narrativos se dão, entre as três vozes que lhe narram, a partir da memória de Lili e também em direção a ela.

\section{A experiência da sobrevivente e a memória que persiste}

"Se o nazismo é a soma de todas as perversões humanas", como afirma Bernardo Lewgoy (em consonância com o pensamento de Elisabeth Roudinesco), "o judeu é uma vítima emblemática que serviu para tornar o horror nazista viável” (2010, p. 52). Muito embora não fossem os únicos perseguidos, não é difícil imaginar que o assassinato brutal de mais de 6 milhões de judeus nos campos de concentração respinga na "vida das retinas tão fatigadas" - para voltar à analogia com o verso drummondiano - de toda a humanidade. Lili Jaffe era judia, e judias também se reconhecem suas descendentes, mas ela, diferente de sua filha e de sua neta, teve uma experiência in loco junto ao povo majoritariamente perseguido pelo Terceiro Reich: foi presa pelo regime, mantida nos campos de concentração, e sobreviveu. Lili foi uma sobrevivente. O seu diário, como já afirmamos, é o seu testemunho pessoal do Holocausto, peça que contribui para a compreensão dos respingos da barbárie e simultaneamente "eterniza" a sua memória; no entanto, o conjunto da obra $O$ que os cegos estão sonhando? talvez dê um passo adiante na busca pela compreensão das sequelas dos campos de concentração justamente por trazer à tona o relato de duas gerações posteriores àquela que experienciou o trauma, estando as duas intimamente vinculadas à memória da sobrevivente.

Como é possível compreender essa memória? Como é possível que a memória de uma mulher seja capaz de influenciar de modo tão significativo as vidas de sua filha e neta? Não pretendemos, em absoluto, dar uma resposta única e soberana ao tema, mas podemos traçar uma linha que dê conta de debatê-lo. Para tanto, vale a pena resgatar o pensamento do filósofo italiano Paolo Rossi:

A memória parece referir-se a uma persistência, a uma realidade de alguma forma intacta e contínua [...] Segundo Aristóteles, a memória [...] pertence à mesma parte da alma que a imaginação: é uma coleção ou seleção de imagens com o acréscimo de uma referência temporal. (2010, p. 15-16, grifo nosso) 
Relacionar a condição da memória a uma persistência parece bastante plausível ao debate que propomos. Por um lado, a experiência anterior que possibilita a memória é exclusiva de Lili Jaffe. Diferente de sua filha e de sua neta, a ela pertenciam pessoalmente as informações daquela realidade, em sua memória ficaram registradas as imagens e sensações do período em que foi presa. Sempre que Lili se propunha a conversar com Noemi sobre a sua experiência, acessava esse conteúdo - por doloroso que pudesse ser relembrá-lo - que é permeado por uma referência temporal comum a todas as outras pessoas que também sobreviveram, embora cada uma tenha o seu registro, a sua memória dos campos de concentração. A persistência da memória atinge um duplo a partir do momento em que Lili decide compartilhá-la, seja por meio do diálogo ou do código escrito, e passa a compor a memória de um outro na medida em que este também pode acessá-la. Tal acesso, no entanto, se realiza unicamente por meio da imaginação, possível quando as referências temporais disponíveis no conhecimento histórico - e coletivo - da humanidade se relacionam com a experiência daquela lida - no caso de quem lê o seu diário, agora na forma de livro - ou ouvida - no caso de sua filha.

Outro sentido pode ser atribuído à memória enquanto persistência: a partir da experiência do outro - neste caso, de Noemi e de Leda - a memória do trauma continua existindo, e, ao que se pode inferir da obra $O$ que os cegos estão sonhando?, quão mais próximos sejam aqueles que de alguma forma "compartilham" tal memória daqueles que a vivenciaram, mais latente ela será na construção de suas identidades, permeada pela busca por compreender um passado que não lhes pertence diretamente, mas que influencia de modo pontual a sua existência. Isso é visível na voz preocupada das demais narradoras: de Noemi, que afirma que

não se pode lembrar o esquecido impunemente. Cavocar a memória do esquecimento é enfiar as mãos em montanhas e labirintos e espelhos e pirâmides de lixo, de sujeira, de monstros, de imagens desconexas, em que uma cena de mãe cozinhando pode estar enganchada numa cena de tortura [...] A memória é uma tirana e a memória daqueles que lembram muito é a pior delas. (JAFFE, 2012, p. 165-166)

E mais claramente - ou, digamos, mais objetivamente - na voz de Leda:

É difícil dimensionar o tamanho do meu passado e a influência fundamental das coisas que aconteceram antes de eu nascer sobre aquilo que eu sou hoje. O passado é uma sombra que acumulamos: uma sombra que não tem peso real, mas que ainda assim desenha uma curva real nas nossas costas [...] Não somos cúmplices da guerra ou dos campos de concentração, porque não estivemos ali, porque viemos depois; mas somos todos cúmplices desta lembrança. (JAFFE, 2012, p. 233-236) 
Vem ao encontro dessa discussão a afirmação de Rossi: "a memória sem dúvida tem algo a ver não só com o passado, mas também com a identidade e, assim (indiretamente), com a própria insistência no futuro" (2010, p. 24). A memória de Lili é parte constitutiva da identidade de Noemi, ato contínuo da identidade de Leda, e discuti-la - ou discutir a forma como se apresenta para cada geração - é uma etapa preliminar para aprofundar o tema que permeia toda essa memória: o trauma. Se o Holocausto pode ser reconhecido "não como uma questão judaica ou alemã mas como uma tragédia de significado universal, que passa pelo reconhecimento de sua dimensão judaica como vítima paradigmática do eliminacionismo nazista" (LEWGOY, 2010, p. 53), o resgate da memória participa daquilo que Rossi chama de "insistência no futuro" na medida em que coloca o trauma no seu epicentro. O trauma já não é apenas a lembrança de um acontecimento na vida das retinas tão fatigadas, mas sim a própria pedra no meio do caminho - no meio da memória.

\section{Noemi Jaffe e a pedra no meio do caminho}

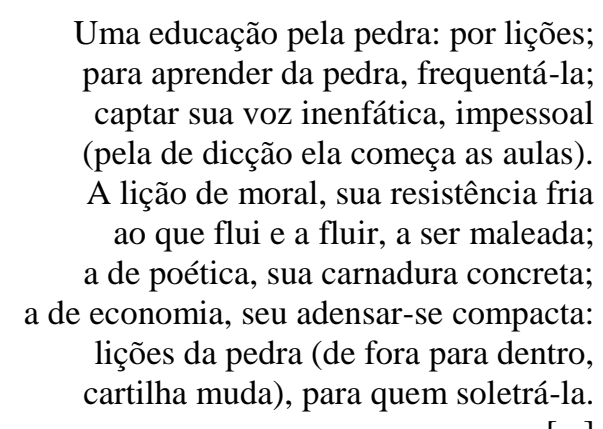

A educação pela pedra, João Cabral de Melo Neto ${ }^{3}$

Insistindo na ideia da função terapêutica da escrita, é preciso que reconheçamos de antemão que a vida de Noemi Jaffe é transpassada pela dedicação à literatura, que lhe confere reconhecimento como crítica literária e também escritora. Não queremos afirmar de início que o trabalho de Noemi em $O$ que os cegos estão sonhando? seja puramente terapêutico, porque correríamos o risco de limitar a análise aqui proposta a uma percepção unicamente psicanalítica, mas também não podemos descartar essa possibilidade. É preciso, para tanto, relacionar a experiência de Noemi ao testemunho de sua mãe. Se a memória desta é constituída pela experiência do trauma, ao qual análoga e propositalmente (como veremos logo a seguir) relacionamos com a imagem da pedra, o seu diário caracteriza, de certa forma,

\footnotetext{
32008 , p. 207.
} 
a materialização desse trauma, pois traduz a memória em persistência, eternizando-a. Logo, o diário é, também ele, a pedra. Noemi tem consciência desse trauma, pois se ele

é um conceito central na psicanálise, e se, por outro lado, ele não pode ser pensado independentemente da noção de realidade traumática, [...] também aquele que se debruça sobre a literatura não pode crer - de modo inocente - que, tanto subjetiva quanto objetivamente falando, o trauma não esteja presente de antemão. (SELIGMANN-SILVA, 2005, p. 64)

Compreender o trauma é o desafio a que Noemi se propõe quando decide discutir o diário, editá-lo, transformá-lo em livro. Por difícil, complexo e doloroso que seja o processo de manipular os dados desse testemunho, dessa memória, o produto se converte em lições a partir da pedra, "lições da pedra [...] para quem soletrá-la".

Márcio Seligmann-Silva (2005), em estudo sobre o trauma e suas relações com a literatura produzida a partir dele, resgata a pesquisa do psicanalista alemão Werner Bohleber em relação ao trauma sofrido pelos sobreviventes do Holocausto, cujos resultados foram dinamizados em simpósio realizado sobre o tema em Copenhague, Dinamarca, em 1967. Entre os diagnósticos e prognósticos resultantes do encontro, chama a atenção o fato de que "os traumatismos sofridos foram além da capacidade de elaboração dos sobreviventes e vieram a marcar a geração seguinte" (BOHLEBER, 2000, p. 814 apud SELIGMANNSILVA, 2005, p. 69). Essa informação corrobora o que já afirmamos em outros momentos a respeito da transmissão - ou da perpetuação, da persistência - da memória de quem sofreu o trauma a seus descendentes. É curioso notar, no entanto, de acordo com Seligmann-Silva, que “pela chamada 'síndrome de sobrevivente' alguns costumem referir-se a si mesmos em terceira pessoa" (2005, p. 68). Lili Jaffe não se refere a si mesma em terceira pessoa, mas sim em primeira pessoa, dotando o diário de toda a dramaticidade inerente ao relato de quem possui a própria experiência como testemunho pessoal e ocular. Tal não ocorre em relação a Noemi: na segunda parte da obra, seção de maior profundidade (e tamanho) cuja autoria lhe corresponde, a autora refere-se a si sempre em terceira pessoa. Ela tem consciência disso e tenta explicá-lo:

\footnotetext{
A filha não quer explicar, não sabe muito bem. Não se sente bem contando esta história-nãohistória em primeira pessoa. Não foi com ela que as coisas aconteceram. Ela é uma voz e só quer ser voz. A terceira pessoa [...] quer desaparecer. Aqui, nesta história, é claro que ela não alcança este poder supremo e inestimável do desaparecimento, mas se aproxima mais dele do que se fosse a primeira pessoa. (JAFFE, 2012, p. 188)
}

É como se Noemi tentasse deliberadamente se distanciar de um discurso que tornaria a história sua, que lhe colocaria no lugar simultâneo de autora e protagonista, ou mesmo coautora e coprotagonista. Daí que tente “desaparecer” por trás da terceira pessoa, elevando o 
reconhecimento - ou suposto protagonismo - a quem primeiro diz respeito a memória. Continua a filha em relação a si: “Aqui, da forma abstrusa como ela aparece, pode até ser que seja uma primeira pessoa disfarçada de terceira, mas é o máximo que a autora-não-autora conseguiu fazer. Ser terceira de si e, principalmente, da mãe, que é a primeira pessoa" (JAFFE, 2012, p. 188).

Se o diário, para além de ser um registro testemunhal do trauma, caracteriza para Lili um caminho terapêutico de superação, a exploração de Noemi sobre ele percorre trilha levemente distinta. Aqui se coloca uma condição anômala em relação ao trauma: enquanto Lili segue na direção de superá-lo, pois a experiência in loco do campo de concentração é unicamente sua, Noemi busca o passado de sua mãe como forma de compreendê-la e, mais ainda, de compreender a sua condição de sobrevivente. Isso fica claro na voz de Noemi na segunda parte da obra, quando comenta trechos do diário ou de diálogos com sua mãe: "ser filho de sobrevivente contém, em algum lugar remoto e inóspito da memória, a tentação de ter estado no lugar do sobrevivente" (JAFFE, 2012, p. 115).

O trauma que provavelmente mais angustie Noemi talvez seja justamente o da pedra, em que sua mãe assumira - mesmo não tendo sido culpada - o roubo de um punhado de margarina e fora obrigada, como punição, a ficar de joelhos sobre tijolos por duas horas, segurando outro sobre a cabeça. ${ }^{4} \mathrm{O}$ termo utilizado para o objeto de punição, no diário, é tijolo; mais adiante, quando transcreve a fala de sua mãe, Noemi utiliza "cascalho" e "pedra". É visível que a substituição de um termo por outro é intencional para Noemi, dada a força simbólica que a pedra pode emanar para o contexto - não por acaso, a própria imagem que ilustra a capa do livro, também da autoria de Noemi, iconiza a pedra a partir do retrato do memorial em Auschwitz onde se colocam pedras para homenagear os mortos no Holocausto. ${ }^{5}$ Tanto que ela afirma: "Não há como dramatizar ou metaforizar esta pedra. E mesmo assim, ela é o acontecimento, o fato que mais está presente na memória, dela e das filhas" (JAFFE, 2012, p. 112). Note-se: Noemi se inclui nesta memória indiretamente, posto que, obviamente, está entre as filhas de Lili. Ela quer dizer, portanto, que essa memória também é sua, embora não lhe pertença; ato contínuo, tenta fazer crer que o trauma também é seu, mesmo que de maneira indireta.

\footnotetext{
${ }^{4}$ No diário, o episódio é narrado no dia 2 de agosto (ano não especificado, mas provavelmente seja 1944). Encontra-se no livro entre as páginas 22 e 25.

${ }^{5}$ De acordo com informações constantes na ficha catalográfica, a foto foi feita em 2009, provavelmente na mesma viagem feita por Noemi com sua filha Leda, marco importante na vida dessas duas mulheres e que dá impulso à produção da terceira parte da obra, escrita por Leda.
} 
Para além da viagem feita a Auschwitz em 2009, com sua filha, pode ser que toda a obra $O$ que os cegos estão sonhando? seja uma tentativa de compreensão desse trauma, dessa memória - que é mais claramente buscada por Noemi, muito mais do que Lili ou do que sua filha, Leda. Mais ainda: embora não seja propriamente um diário, pode ser que a seção de sua autoria, em que comenta excertos do diário ou de diálogos com sua mãe, também seja uma espécie de "diário" como exercício terapêutico, em que sua reflexão dialoga com a memória sua e de um outro, que é, neste caso, a da sua mãe - na tentativa de compreendê-la. Daí que se assimile a vontade de ter estado no lugar do sobrevivente: “o desejo de salvar a mãe é o desejo de extirpar da memória o sofrimento da mãe para que se possa libertar-se dele, para que se possa viver sem a pedra” (JAFFE, 2012, p. 115), libertação que, se possível, se dirigiria não apenas à mãe, mas também à filha em relação à memória.

A condição de autora e de editora coloca Noemi em posição de falsa superioridade, de um suposto controle em relação ao diário, quando na verdade ela se subordina a ele: busca nele a compreensão de um passado que não viveu, de uma memória que não é diretamente sua, mas que ainda assim constrói a sua identidade, a sua experiência de vida. O diário é a sua pedra no meio do caminho, como símbolo de uma memória que transcende a sua própria vida e que lhe impõe uma adversidade existencial de maneira perene; de modo que, abusando mais uma vez dos versos de Drummond, o eu-lírico poderia ser refletido pela voz de Noemi: Nunca me esquecerei desses acontecimentos/ na vida de minhas retinas tão fatigadas./ Nunca me esquecerei que no meio do caminho/ tinha uma pedra.

\section{Leda Cartum e o relato consciente sobre a memória}

Retomando o estudo de Seligmann-Silva, em expansão ao conceito de transposição do trauma dos sobreviventes para os seus descendentes, o autor coloca que "em certos casos, a identificação com o sofrimento dos pais levou ao que já foi denominado de 'télescopage' de duas ou até três gerações: um desastre de engavetamento múltiplo que reduz três gerações ao espaço do tempo - fora do tempo! - do trauma" (2005, p. 69). A citação seria perfeita se o texto de Leda acompanhasse esse suposto "desastre" (que, no nosso caso, é mais uma "pedra no meio do caminho" do que uma tragédia) e se limitasse a questionar a memória de sua avó na busca de compreendê-la, como faz sua mãe. Entretanto, o que se extrai dela - da citação é somente a certeza de que a identificação com o sofrimento pode alcançar os netos, para além dos filhos, porque o discurso de Leda se caracteriza como um passo adiante nessa busca por 
uma compreensão que, mesmo não encontrando respostas sólidas e objetivas, a despeito da geração anterior, culmina numa consciência mais madura em relação ao trauma.

O texto de Leda, na última parte do livro, é o mais curto de todos. Não por acaso, está no polo oposto ao diário de sua avó, separado deste por um intermediário que absorve quase que exclusivamente a angústia por compreender a memória traumática. Leda Cartum não questiona o trauma com a intenção de compreender a sua existência, porque aparentemente a sua consciência em relação ao tema já alcança, em certa medida, maior maturidade. Se no início ela afirma que "era difícil (ainda é) entender o tamanho da identidade que eu carregava, embora sempre soubesse que carregava alguma coisa que me constituía" (JAFFE, 2012, p. 234), o modo como explicita a sua reação ao chegar a Auschwitz com sua mãe, em 2009, denota que o pertencimento do trauma não lhe atinge com a mesma intensidade: "quando entramos juntas em Auschwitz, minha mãe e eu, eu não senti nada [...] Eu não queria estar ali” (JAFFE, 2012, p. 231). Não significa, em absoluto, que esse não querer tenha se dado por birra, por descaso, por indiferença, mas sim que a sua compreensão sobre o tema não prioriza com a mesma intensidade a busca por entender a constituição senão da sua própria identidade, pelo menos da identidade comum da sua família, balizada pela memória do trauma vivenciado por Lili Jaffe. Isso talvez ocorra porque Leda possui uma referência anterior - ou seja, seus pais - já bem constituída, e coube a eles se comunicar primeiro com o trauma (relacionado, no caso de sua mãe, por uma ligação íntima e direta com a sobrevivente, sua avó) para que só depois chegasse a ela. A consciência "madura" de Leda fica clara em passagem como esta:

Ser neta de sobreviventes é ter uma relação indireta com este sofrimento que possibilitou a minha existência. Porque há entre mim e o sofrimento um intermediário, alguém que já desbravou o matagal sórdido do trauma: nasci numa clareira, o terreno limpo e pronto, bem cuidado, porque meus pais se encarregaram de tirar as ervas daninhas, arar a terra, semear. (JAFFE, 2012, p. 234)

Ao mesmo tempo, Leda compreende a relação de sua mãe com a memória de sua avó, compreende a busca que se empreende pelo passado que não lhe pertence e que ao mesmo tempo lhe constitui, lhe permite vida. Nesse sentido, é possível que seja ela quem dê uma resposta mais clara para justificar a ação que se articula no texto de sua mãe: "Talvez esse seja um dos destinos marcados daqueles que descendem dos sobreviventes: a necessidade de recuperar algo que não pode ser recuperado, a constante sensação de estar puxando uma linha cujo anzol não fisgou nada, apesar de muito" (JAFFE, 2012, p. 235).

A maturidade consciente de Leda é transpassada pela noção daquilo que ela mesma chama de "milagre da simultaneidade" - pela consciência de que as coisas acontecem ao mesmo tempo. Ela conta que desde a infância foi "atormentada" pela inquietação de saber 
como é possível estar deitada dentro do quarto enquanto alguém nasce, alguém morre, alguém chora em qualquer lugar do mundo (cf. JAFFE, 2012, p. 232). Essa simultaneidade, que se percebe espacial, se revelou para ela também temporal quando esteve em Auschwitz. "Perceber que enquanto estou aqui, vivendo a minha vida", afirma Leda, "as coisas que já passaram, relacionadas ou não com a minha existência, continuam acontecendo e ecoando por todos os lados" (JAFFE, 2012, p. 233). É possível inferir que ela reconhece, portanto, que a memória de seus pais e principalmente a de seus avós é e sempre será simultânea à sua existência. Por reconhecer tal influência, o milagre da simultaneidade também ocorre dentro dela:

Sempre tive espaços internos que não consigo alcançar; como se fossem poços verticais e muito fundos, que sei que existem e que guardam muita coisa, mas aos quais nem sempre tenho acesso. Histórias que fazem parte necessária daquilo que sou e da maneira como me comporto, mas que não vivi nem conheço. (JAFFE, 2012, p. 234)

Saber que essas lacunas, esses espaços inalcançáveis nem sempre estão disponíveis é característico de uma maturidade consciente em relação a tal simultaneidade. Ela não viveu o passado de sua avó; mesmo que leia seu diário, não conhecerá aquela realidade no todo, não terá acesso a esse conhecimento em sua totalidade. Mas sempre será consciente de que essa memória é determinante para a sua constituição enquanto ser humano, para sua própria existência. A afirmação seguinte de Leda, de que "o judaísmo que foi crime e proximidade da morte para meus avós, para mim subsiste e se mantém sempre um pouco deslocado em relação às outras coisas" (JAFFE, 2012, p. 234), pode configurar uma metáfora para a sua relação com o trauma de sua avó: se substituímos o judaísmo pela memória da experiência traumática, percebemos, mais uma vez, que a sua relação com essa memória não coloca a própria relação em uma posição de prioridade, embora não negue a importância de tais lembranças para a sua vida - como uma memória subsistente.

\section{Considerações finais}

Em exercício consciente das relações possíveis a partir da memória de sua avó, e sendo também consciente das relações que se desdobram a partir dessa lembrança reconhecendo até mesmo aquilo que não se tem resposta, não se tem acesso -, Leda sintetiza, ao final de seu relato, um pensamento que viemos desenvolvendo ao longo da nossa discussão: 
Minha avó, em seu diário, de fato se lembra, porque de fato viveu: compartilha conosco suas memórias ainda frescas, reais como nada que poderíamos jamais escrever ou lembrar. É preciso sentar-se e ler as palavras da minha avó. É preciso conhecer essas palavras que guardam, cada uma, uma verdade que não conhecemos - e que no entanto apalpamos, apalpamos e não sentimos nada. (JAFFE, 2012, p. 237)

Não é que não se sinta absolutamente nada, porque nenhum leitor passa impune à leitura de uma obra como essa. Mas é precisamente por ser um testemunho que o diário de Lili permite que conheçamos, como leitores, um pouco daquela realidade, que é bastante sua e que ela decide compartilhar, embora nos seja vedado o acesso às sensações puras, intimamente vinculadas à sua memória. Esta, preenchida por verdades desconhecidas, só pertence a Lili; por mais que se tente apalpá-la, alcançá-la, só nos restará o assombro diante do relato do horror que caracterizou a experiência de quem sobreviveu aos campos de concentração.

Recuperemos, portanto, um questionamento levantado por Bernardo Lewgoy: "se o Holocausto é um drama judaico excepcional, como humanizar e universalizar seu significado, comunicando-o com o de tantas outras vítimas de genocídios? Como realizar uma pedagogia preventiva de novas catástrofes que sirva a judeus e não judeus?” (2010, p. 51). É difícil pensar uma pedagogia que promova a prevenção de tragédias como o Holocausto; mais difícil ainda quando começam a se aproximar do poder - ou mesmo a tomá-lo -, em distintas partes do mundo, figuras com ideais bastante extremistas e, digamos, controversos no que diz respeito à migração, à tolerância racial, sexual e religiosa, que não parecem muito dispostos a um debate preocupado com a integridade da vida humana. Mas o que isso tem a ver com o tema que tratamos ao longo deste artigo?

$O$ que os cegos estão sonhando? constitui uma obra singular: de um lado, traz a memória de Lili Jaffe a partir de sua experiência nos campos de concentração em forma de diário, que é o registro por escrito do testemunho de alguém que sobreviveu à barbárie. Esse testemunho em primeira pessoa sela e ao mesmo tempo abre a chaga do trauma de Lili. Os textos de Noemi, sua filha, e de Leda, sua neta, na composição da obra como um todo, representam a cicatriz desse trauma sobre a memória comum dessas três gerações de mulheres - marca que arde mais para uma do que para a outra, mas que participa da constituição e da história de vida de ambas. O centro de tudo, portanto, é a memória de Lili: sem ela, nada teria acontecido. Se Lili não tivesse sobrevivido, Noemi e Leda não existiriam e esse testemunho jamais teria sido escrito. A função de uma obra como $O$ que os cegos estão sonhando?, a partir do momento em que discute a memória do Holocausto, coloca em jogo uma discussão que possivelmente vem ao encontro de humanizar o seu significado. No âmbito de sua feliz 
existência, a obra pode ser um pilar para comunicar ao mundo, por meio e a partir da memória de uma sobrevivente, uma pedagogia que talvez não alcance prevenir novos genocídios, mas que deixa a cicatriz aberta, que coloca seus leitores em choque - e em estado de alerta.

\section{Referências}

ANDRADE, Carlos Drummond de. Alguma poesia; posfácio de Eucanaã Ferraz. São Paulo: Companhia das Letras, 2013.

JAFFE, Noemi. O que os cegos estão sonhando?: com o diário de Lili Jaffe (1944-1945) e texto final de Leda Cartum. São Paulo: Editora 34, 2012.

LEWGOY, Bernardo. Holocausto, trauma e memória. WebMosaica: revista do Instituto Cultural Judaico Marc Chagall, Porto Alegre, v. 2, n. 1, p. 50-56, jan./jun. 2010.

MELO NETO, João Cabral de. A educação pela pedra e outros poemas. Rio de Janeiro: OBJETIVA, 2008.

ROSSI, Paolo. Lembrar e esquecer. In: O passado, a memória, o esquecimento: seis ensaios da história das ideias. Tradução de Nilson Moulin. São Paulo: Editora UNESP, 2010. p. 15-38.

SELIGMANN-SILVA, Márcio. Literatura e trauma: um novo paradigma. In: . O local da diferença: ensaios sobre memória, arte, literatura e tradução. São Paulo: Editora 34, 2005. p. 63-80. 